\title{
Interactive effect of combined exposure to ethylene glycol ethers and ethanol on hematological parameters in rats
}

\author{
Andrzej Starek1, Katarzyna Miranowicz-Dzierżawska ${ }^{2 *}$, Beata Starek-Świechowicz ${ }^{1}$ \\ ${ }^{1}$ Department of Biochemical Toxicology, Medical College, Jagiellonian University, Krakow, Poland \\ ${ }^{2}$ Department of Chemical and Aerosol Hazards, Laboratory of Toxicology, Central Institute for Labour Protection—National Research \\ Institute, Warsaw, Poland; Corresponding Author: kamir@,ciop.pl
}

Received 23 April 2010; revised 14 May 2010; accepted 16 May 2010.

\section{ABSTRACT}

The study of the interaction of three glycol ethers, i.e. 2-methoxyethanol (ME), 2-ethoxyethanol (EE) and 2-butoxyethanol (BE) administered subcutaneously for 4 weeks and ethanol simultaneously given as $10 \% \mathrm{w} / \mathrm{v}$ solution for drinking in male rats, was carried out from a toxicodynamic point of view. Administered alone, ME (2.5 and $5.0 \mathrm{mM} / \mathrm{kg})$, EE (2.5 and $5.0 \mathrm{mM} / \mathrm{kg})$ or BE (0.75 and $1.25 \mathrm{mM} / \mathrm{kg}$ ) resulted in a decrease of red blood cells (RBC), packed cell volumes (PCV), and hemoglobin concentration (HGB), as well as an increase in mean corpuscular volume (MCV) and reticulocyte count (Ret). In the rats co-exposed to ethanol and EGAEs, a significantly less pronounced hematological changes in comparison with animal exposed to these ethers alone were seen. The rats simultaneously exposed to ethanol and both ME and EE at the lower dose demonstrated mainly protection from the alterations in leukocyte system. In contrast, in the rats which consumed ethanol and were simultaneously treated with the higher dose of ME or EE $(5.0 \mathrm{mM} / \mathrm{kg})$ the amelioration of same hematological parameters were displayed. The intake of ethanol along with BE treatment at both doses resulted in markedly ameliorated hematological parameters, compared to those which were changed by $B E$ alone. In conclusion, the decrease of the hemolytic effects of EGAEs is ethanol dependent. Ethanol is a substrate of alcohol dehydrogenase (ADH), and affinity of this enzyme to ethanol is greater than that to glycol ethers. It is possible that ethanol results in the change in EGAEs metabolism.

Keywords: Ethylene Glycol Alkyl Ethers; Ethanol;
Repeated Exposure; Toxicodynamic Interactions

\section{INTRODUCTION}

Ethylene glycol alkyl ethers (EGAEs), i.e., 2-methoxyethanol (ME), 2-ethoxyethanol (EE), and 2-butoxyethanol (BE) are extensively used as water-miscible organic solvents in industrial and household applications. Ingestion, inhalation, and/or dermal absorption of these compounds may lead to adverse testicular, teratogenic and hematological effects in animals and humans. These ethers may cause local toxicity, i.e., skin irritation and sensitization in susceptible humans [1] and also, systemic toxicity. The primary systemic toxicity of these chemicals in animals include reproductive, developmental and hematological effects [2-6]. Similar effects have been observed in exposed workers. The hematological toxicity of ME resulted in marrow depression, leukopenia, pancytopenia, and decreased red blood cells count (RBC), hemoglobin concentration (HGB), and platelet count $[7,8]$. Shih et al. [9] showed that the HGB, packed cell volume (PCV), and RBC in male workers exposed to $\mathrm{ME}$ for 2.6 years were significantly lower relative to controls. Also, the frequency of anemia in the exposed group (26.1\%) was significantly higher, with respect to their corresponding control group (3.2\%). Moreover, RBC was significantly negatively associated with air concentrations of ME, whereas $\mathrm{HGB}, \mathrm{PCV}$, and $\mathrm{RBC}$ were negatively correlated with urinary concentrations of methoxyacetic acid (MAA), a metabolite of ME. These hematological effects were reversible, and they had returned to normal after reduction in ME exposure [10].

Other survey of male shipyard painters exposed to mixed solvents containing EE acetate suggests that this compound might be toxic to bone marrow [11], whereas in female workers chronically exposed to high concentrations of EE, average RBC and HGB levels were nor- 
mal [12]. In male workers exposed to low concentration of BE, a statistically significant decrease in $\mathrm{PCV}$ value and an increase in mean cell hemoglobin concentration (MCHC) value were observed [13].

EGAEs can produce toxicity following oxidation to the corresponding aldehyde and alkoxyacetic acid by alcohol dehydrogenase (ADH; EC 1.1.1.1) and aldehyde dehydrogenase (ALDH; EC 1.2.1.3), respectively. Both the alkoxyacetaldehyde and alkoxyacetic acid metabolites of the EGAEs are considered to be toxic agents [14,15].

The metabolic activation of EGAEs by ADH and ALDH leads to the appearance of their toxic effects $[16,17]$. Butoxyacetic acid (BAA), a metabolite of BE, is thought to be a more efficacious hemolytic agent than the parent compound in vitro, and causes similar hemolytic changes in vivo $[17,18]$.

The inhibition of ADH by pyrazole or 4-methylpyrazole is known to decrease the hemolytic effect of BE $[17,19]$ and the urinary excretion of BAA [16,17]. The simultaneous administration of BE with ethanol, n-propanol or n-butanol to rats almost totally inhibited the hemolytic effect of this chemical, and decreased the urinary excretion of BAA. In contrast, the co-administration of ethanol with ME did not modify the urinary excretion of MAA, but induced accumulation of this metabolite in rats $[20,21]$. These data mainly arise from acute experiments.

This study presents the results of an investigation into hematological changes in peripheral blood of rats simultaneously exposed to EGAEs and ethanol for 28 days. Ethanol and other primary alcohols are used in industrial solvent compositions containing glycol ethers and are metabolized by ADH and ALDH.

In addition, the excessive consumption of ethanol by a large part of the workers may lead to interactions with EGAEs.

\section{MATERIALS AND METHODS}

\subsection{Chemicals}

$\mathrm{ME}$, EE, and BE were purchased from Sigma-Aldrich Ltd, Poland. Other chemicals were obtained from POCh (Poland). ME, EE, and BE solutions were prepared in saline, immediately before dosing, and administered to rats by subcutaneous injections in a fixed volume of 2.0 $\mathrm{ml} / \mathrm{kg}$ body weight, regardless of a dose.

\subsection{Experimental Animals}

Experiments were performed on 12-week-old male Wistar rats (Krf: (WI)WUBR), with an initial body weight of $319 \pm 22.4 \mathrm{~g}$, and obtained from Jagiellonian University Faculty of Pharmacy Breeding Laboratory (Kraków, Po- land). The animals were kept under standard laboratory conditions (temperature $21 \pm 2^{\circ} \mathrm{C}$; relative humidity $50 \pm$ $10 \%$ ) with a $12 \mathrm{~h}: 12 \mathrm{~h}$ (light:dark) cycle and had free access to drinking water free of ethanol or $10 \% \mathrm{w} / \mathrm{v}$ ethanol solution, and standard pellet Murigran chow (Agropol, Motycz, Poland) during the experimental period.

\subsection{Experimental Design}

The rats were randomly divided into fourteen groups of five animals each. The rats (six groups) had free access to drinking water and were treated with $\mathrm{ME}$, and $\mathrm{EE}$ at doses of 2.5 , and $5.0 \mathrm{mM} / \mathrm{kg}$ or BE at doses of 0.75 , and $1.25 \mathrm{mM} / \mathrm{kg}$, 5 days per week, for 4 weeks. Control rats (one group) received drinking water at libitum.

An ethanol groups (six groups) had free access to an aqueous solution of ethanol $(10 \% \mathrm{w} / \mathrm{v}$ solution of rectified spirit POLMOS, Poland) as the only drinking fluid and were treated by subcutaneous injections with ME, $\mathrm{EE}$ or $\mathrm{BE}$ at the doses mentioned above. Control rats (one group) drank $10 \% \mathrm{w} / \mathrm{v}$ ethanol, but were not exposed to $\mathrm{ME}, \mathrm{EE}$ or $\mathrm{BE}$.

The rats were observed daily and were weighed once weekly, whereas the consumption of an aqueous solution of ethanol and food was measured daily during the whole experiment.

Before experiment, during exposure and after its termination, i.e., at $0,4,11,18$, and 29 day, blood samples from the tail vein of rats were collected for hematological analyses.

The study was accepted by the Local Ethical Committee for animal experiments in Kraków. Procedures involving the animals and their care conformed to the institutional guidelines, in compliance with national and international laws and Guidelines for the Use of Animals in Biomedical Research.

\subsection{Hematological Analyses}

Heparin-added whole blood samples, immediately after collection, were used for hematological analyses. RBC, $\mathrm{PCV}$, mean corpuscular volume (MCV), HGB, MCHC, and mean cell hemoglobin $(\mathrm{MCH})$ were analyzed by means of a COBAS MICROS (Roche, Palo Alto, CA, USA) analyzer. Reticulocyte count (Ret) was evaluated after staining blood samples (without anticoagulant) with brilliant-cresol blue. White blood cells (WBC) were counted by a hemacytometer after diluting the fresh blood samples (without anticoagulant) by Türk's reagent solution. The differential white cell count was evaluated after Pappenheim-stained blood films.

Hematological analyses were systematically checked by means of standard human blood CBC-3D Hematology Control (R\&D System Inc., Minneapolis. MN, USA). 
A day-to-day precision of RBC, PCV, and MCV measurement $(\mathrm{n}=30)$ in blood was $4.2,4.5$, and $4,4 \%$, respectively.

\subsection{Statistical Analyses}

Results are expressed as the mean $\pm \mathrm{SD}$. Data were analyzed by two-way analysis of variance with repeated measurements on one factor and evaluation of simple effects (MANOVA). The analysis was performed with the SPSS 12.0 statistical packet (SPSS Inc., Chicago, IL, USA). For comparison of exposed groups with control group and exposed groups to $\mathrm{ME}, \mathrm{EE}$ or $\mathrm{BE}$ alone with groups simultaneously treated with these compounds and ethanol at each point of time, one-way analysis of variance (ANOVA) followed by Dunnett test was used. Probabilities lower than 0.05 were considered significant.

\section{RESULTS}

Ethanol intakes in the ethanol alone and co-exposed to ethanol and EGAEs groups were similar, when expressed in $\mathrm{mM} / \mathrm{kg}$ b.w./24 h (Table 1).

Control rats consumed in average $59.6 \pm 9.3 \mathrm{~g} / \mathrm{kg}$ b.w./24 h of Murigran food during the 4 week experiment. The food consumption in the ethanol group and in the co-exposed to ethanol and ME at a dose of 2.5 $\mathrm{mM} / \mathrm{kg}$ group was similar to that of the control rats. In other co-exposed groups, simultaneously treated with ethanol and EGAEs, the food intake was significantly diminished by mean $31 \%$ in comparison to the control group (Table 1).

Body weight gain in both control and ethanol-drinking groups was similar. An increase in the body weight, at the end of exposure, in ethanol-drinking rats and simul- taneously treated with $\mathrm{ME}$, and $\mathrm{EE}$ at a dose of 2.5 $\mathrm{mM} / \mathrm{kg}$ or exposed to $\mathrm{BE}$ at a dose of $0.75 \mathrm{mM} / \mathrm{kg}$ was significantly lower in comparison to both control and ethanol groups. The rats co-exposed to ethanol and ME or EE at a dose of $5.0 \mathrm{mM} / \mathrm{kg}$ and $\mathrm{BE}$ at a dose of 1.25 $\mathrm{mM} / \mathrm{kg}$ lost weight by $42.7 \pm 5.1,28.0 \pm 6.2$, and $11.0 \pm$ $0.6 \mathrm{~g}$, respectively (Table $\mathbf{1}$ ).

\subsection{Hematological Changes}

The consumption of ethanol alone for 4 weeks had no effect on hematological parameters. ME administration at doses of 2.5 and $5.0 \mathrm{mM} / \mathrm{kg}$ resulted in a decrease of RBC, PCV, and HGB that occurred from 11th day of exposure to its termination and in an increase in the Ret exclusively at the end of exposure. At the end of experiment, i.e., on day 29 , the greatest changes of RBC, PCV, HGB, and Ret were observed (Figure 1). These hematological parameters demonstrated dose, both dose and time, and time dependence.

In the rats co-exposed to ethanol and ME, significantly less pronounced hematological changes were seen, mainly in HGB, PCV and MCH (Figure 1).

Hematological changes in the peripheral blood of rats treated with $\mathrm{EE}$ alone were less pronounced than those after ME administration. The lower dose of this compound $(2.5 \mathrm{mM} / \mathrm{kg})$ resulted only in a decrease of HGB and an increase of MCV on days 11 and 18 of experiment. The higher dose of EE $(5.0 \mathrm{mM} / \mathrm{kg})$ led to a significant decrease in RBC, PCV, HGB, as well as to an increase in $\mathrm{MCV}$ and Ret for most of the exposure time. These hematological changes demonstrated dose dependence and both dose and time, and time independence (Figure 2).

In the rats simultaneously treated with $\mathrm{EE}$ at the higher dose $(5.0 \mathrm{mM} / \mathrm{kg})$ and ethanol, $\mathrm{RBC}, \mathrm{PCV}$, and

Table 1. Effects of ethylene glycol alkyl ethers on an average ethanol and food consumption and body weight gain in rats.

\begin{tabular}{|c|c|c|c|}
\hline Group & $\begin{array}{l}\text { Ethanol intake } \\
(\mathrm{mM} / \mathrm{kg} \text { b.w. } / 24 \mathrm{~h})\end{array}$ & $\begin{array}{c}\text { Food intake } \\
(\mathrm{g} / \mathrm{kg} \text { b.w. } / 24 \mathrm{~h})\end{array}$ & $\begin{array}{l}\text { Body weight gain } \\
\quad(g / 4 \text { weeks })\end{array}$ \\
\hline Control $^{1}$ & & $59.6 \pm 9.3$ & $+24.3 \pm 0.9$ \\
\hline $10 \%$ Ethanol & $123.1 \pm 18,9$ & $52.3 \pm 6.2$ & $+23.0 \pm 0.8$ \\
\hline $\mathrm{ME}(2.5 \mathrm{mM} / \mathrm{kg})+10 \%$ ethanol & $90.3 \pm 20,0$ & $55.5 \pm 8.7$ & $+2.4 \pm 0,2^{* \dagger}$ \\
\hline $\mathrm{ME}(5.0 \mathrm{mM} / \mathrm{kg})+10 \%$ ethanol & $115.0 \pm 23.9$ & $36.6 \pm 3.9^{* \dagger}$ & $-42.7 \pm 5.1^{* \dagger}$ \\
\hline $\mathrm{EE}(2.5 \mathrm{mM} / \mathrm{kg})+10 \%$ ethanol & $136.7 \pm 1.9$ & $42.7 \pm 3.4^{*^{\dagger}}$ & $+4.0 \pm 0.4^{* \dagger}$ \\
\hline $\mathrm{EE}(5.0 \mathrm{mM} / \mathrm{kg})+10 \%$ ethanol & $145.3 \pm 16.0$ & $39.2 \pm 5.8^{*^{\dagger}}$ & $-28.0 \pm 6.2^{* \dagger}$ \\
\hline $\mathrm{BE}(0,75 \mathrm{mM} / \mathrm{kg})+10 \%$ ethanol & $130.0 \pm 3.1$ & $42.3 \pm 3.7^{* \dagger}$ & $+4.0 \pm 0.1^{* \dagger}$ \\
\hline $\mathrm{BE}(1,25 \mathrm{mM} / \mathrm{kg})+10 \%$ ethanol & $124.0 \pm 6.2$ & $43.2 \pm 4.1^{* \dagger}$ & $-11.0 \pm 0.6^{* \dagger}$ \\
\hline
\end{tabular}

${ }^{1}$ The rats had free access to drinking water. Values are the means \pm SD of 5 animals/group. $p<0.05$ compared to control $(*)$ and ethanol ( $\dagger$ ) group. 


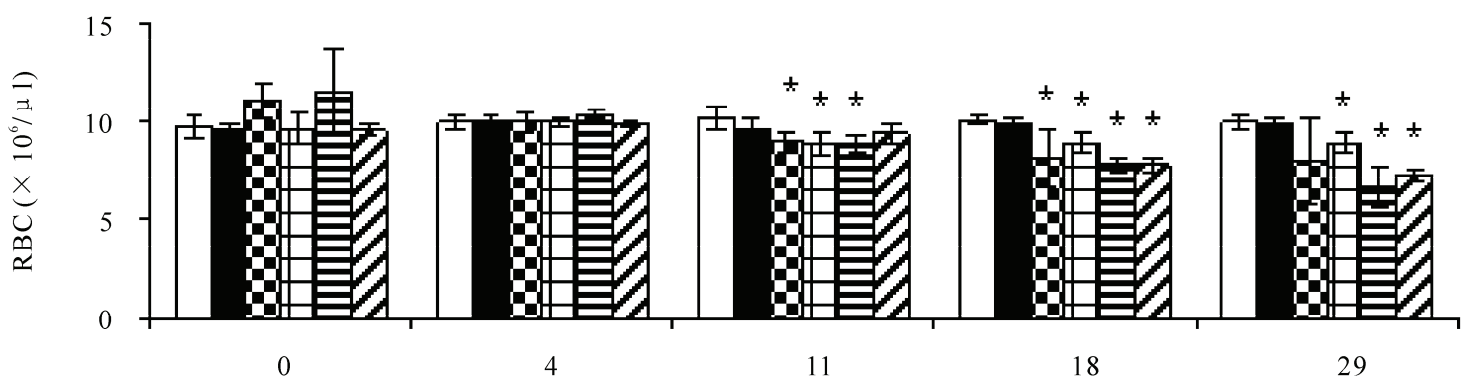

(a)

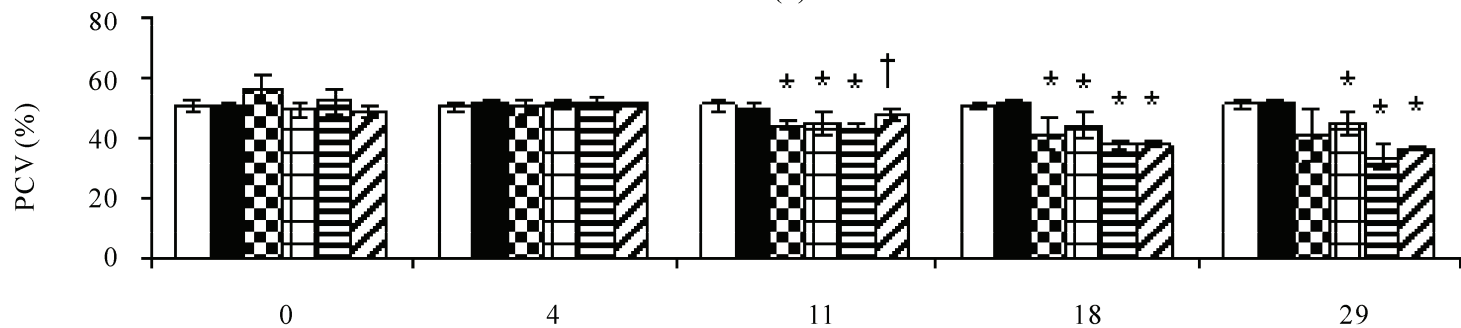

(b)

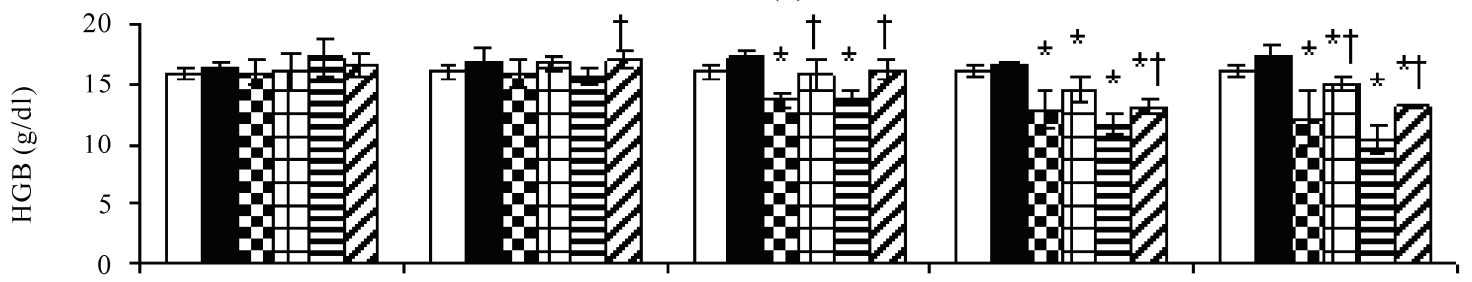

4

11

18

29

(c)

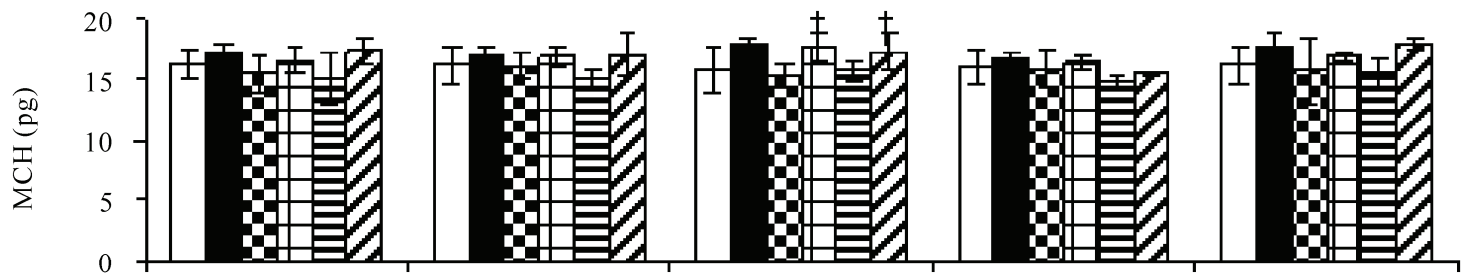

0

4

11

18

29

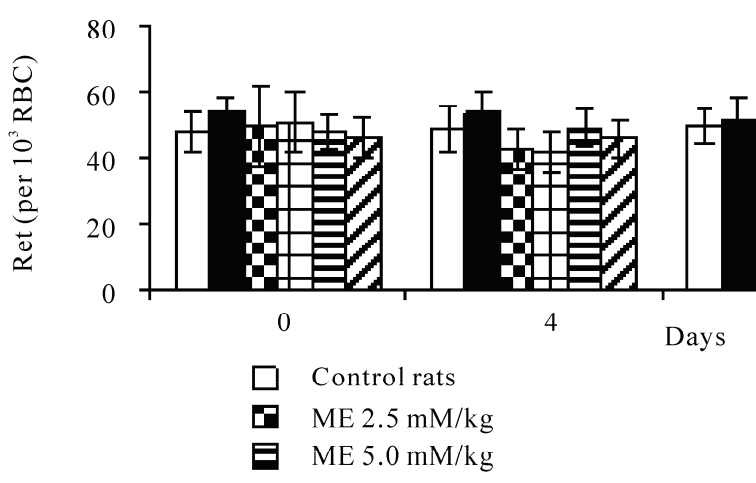

(d)

(e)

Figure 1. Effects of ethanol (EtOH) consumption on RBC (a), PCV (b), HGB (c), MCH (d) and Ret (e) values of the peripheral blood at the designated time points of male rats treated with methoxyethanol (ME) at doses $2.5 \mathrm{mM} / \mathrm{kg}$ b.w. or $5.0 \mathrm{mM} / \mathrm{kg}$ b.w. The values are means $\pm \mathrm{SD}$ of five rats, *-P $\leq 0,05$ significantly different from control rats; $\uparrow-$ $\mathrm{P} \leq 0,05$ significantly different from rats treated with $\mathrm{ME}$ alone. 


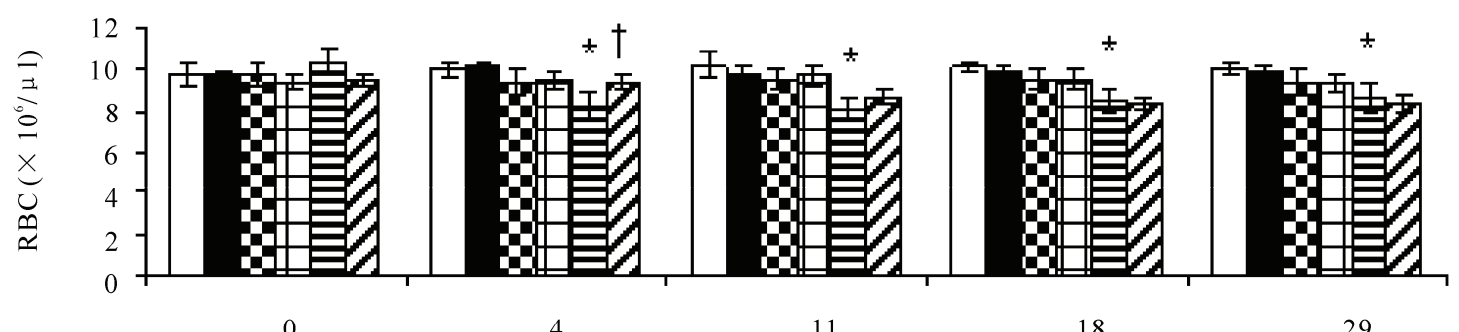

(a)
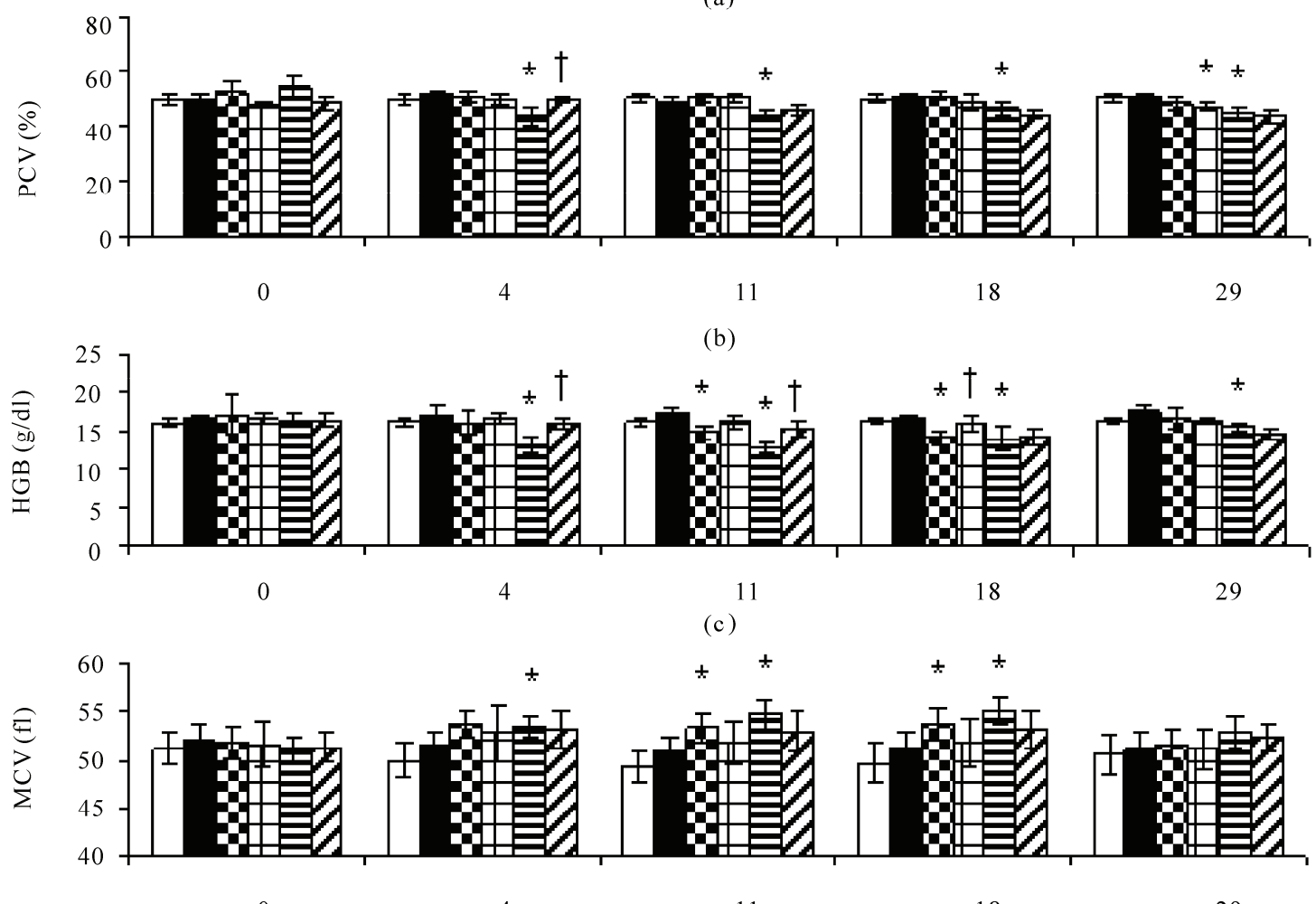

0

(d)

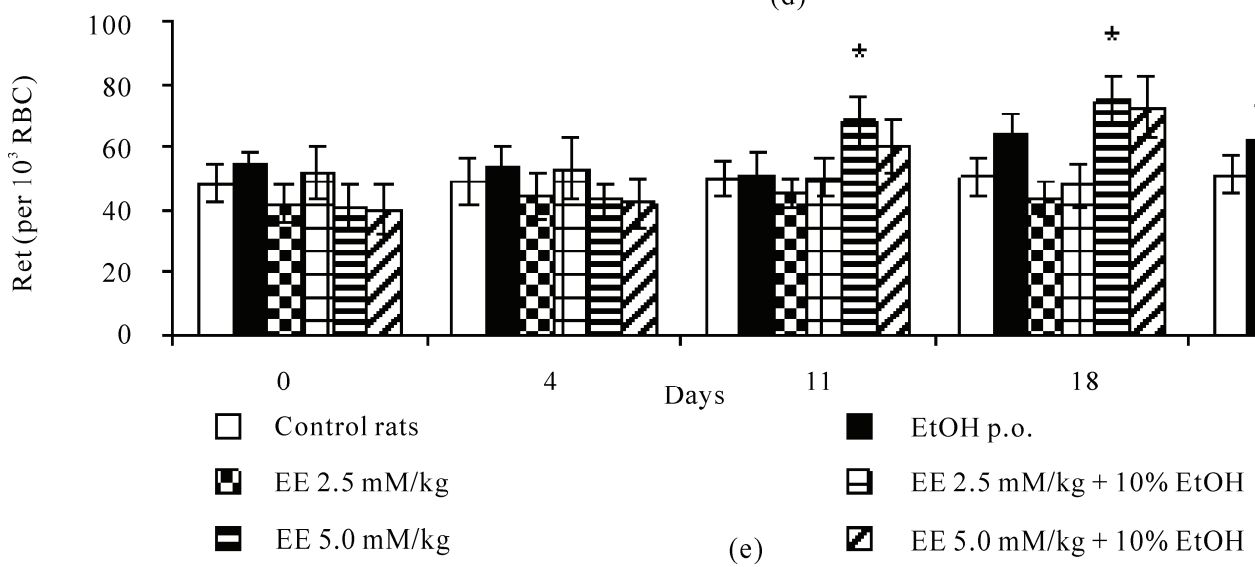

Figure 2. Effects of ethanol (EtOH) consumption on RBC (a), PCV (b), HGB (c), MCV (d) and Ret (e) values of the peripheral blood at the designated time points of male rats treated with ethoxyethanol (EE) at doses $2.5 \mathrm{mM} / \mathrm{kg}$ b.w. or $5.0 \mathrm{mM} / \mathrm{kg}$ b.w. The values are means $\pm \mathrm{SD}$ of five rats, ${ }_{-}-\mathrm{P} \leq 0.05$ significantly different from control rats; $\dagger-\mathrm{P} \leq 0.05$ significantly different from rats treated with EE alone. 
HGB at day 4, and HGB at day 11, were significantly higher than in the rats exposed to EE alone. These parameters did not differ in comparison to the control group (Figure 2).

$\mathrm{BE}$ administration at doses of 0.75 and $1.25 \mathrm{mM} / \mathrm{kg}$ resulted in a decrease in $\mathrm{RBC}, \mathrm{PCV}$, and $\mathrm{HGB}$ and an increase in $\mathrm{MCV}$, and Ret. The greatest changes of $\mathrm{RBC}$, $\mathrm{PCV}$, and HGB were observed at day 4 of experiment, whereas other hematological alterations (MCV, and Ret) showed a maximum on day 11 of the exposure. The changes in $\mathrm{RBC}, \mathrm{MCV}$, and Ret during exposure period were persistent, whereas alterations in PCV, and HGB independently on duration of exposure, were reversible (Figure 3).

In the rats co-exposed to $\mathrm{BE}$ and ethanol, the values of $\mathrm{RBC}, \mathrm{PCV}$, and HGB were significantly higher, whereas $\mathrm{MCV}$, and Ret were markedly lower in comparison to the rats treated with BE alone (Figure 3). Some of hematological parameters ( $\mathrm{HGB}, \mathrm{MCV}$, and $\mathrm{MCHC}$ ) in rats exposed to $\mathrm{BE}$ at a lower dose $(0.75 \mathrm{mM} / \mathrm{kg})$ and ethanol were similar to those in the control group.

\subsection{Leukocyte Alterations}

The leukocyte counts were markedly reduced at each dose of ME from the $4^{\text {th }}$ day of exposure to its termination. These alterations were caused by a decrease mainly in the number of lymphocytes. Also, reductions in number of neutrophils in rats treated with $\mathrm{ME}$ at a dose of $5.0 \mathrm{mM} / \mathrm{kg}$ at days 11 and 18 of the experiment were observed. Both leukocyte and lymphocyte alterations at a dose of $5.0 \mathrm{mM} / \mathrm{kg}$ demonstrated dose, dose and time, and time dependence (Figure 4).

The rats simultaneously exposed to ethanol and the lower dose of ME $(2.5 \mathrm{mM} / \mathrm{kg})$ showed a lack of changes in both leukocyte and lymphocyte counts in comparison to control group at days 11 , and 18 of the experiment. The number of lymphocytes in those animals at days 18 and 29 of the experiment was significantly lower than in the control group, but statistically higher in comparison to the rats treated with $\mathrm{ME}$ alone. In the rats co-exposed to ethanol and the higher dose of $\mathrm{ME}(5.0 \mathrm{mM} / \mathrm{kg})$, the leukocyte and lymphocyte counts were significantly diminished in comparison to the control group, but very similar as in the group exposed to ME alone. Also, the reduction of the number of neutrophils at days 11,18 , and 29 was observed (Figure 4).

No significant leukocyte and lymphocyte alterations in rats exposed to $\mathrm{EE}$ at a dose of $2.5 \mathrm{mM} / \mathrm{kg}$ were observed. In the rats treated with EE alone at the higher dose $(5.0 \mathrm{mM} / \mathrm{kg})$ the leukocyte counts at day 4 and 18 of the experiment were statistically lower than in the control group. The number of lymphocytes in these rats was reduced in comparison to the control group during the whole of exposure period (Figure 5).

The number of both leukocytes and lymphocytes in the rats co-exposed to $\mathrm{EE}$ at a dose of $2.5 \mathrm{mM} / \mathrm{kg}$ and ethanol only at day 4 of the experiment was significantly higher in comparison to group treated with EE alone. In the rats simultaneously exposed to ethanol and EE at the higher dose $(5.0 \mathrm{mM} / \mathrm{kg})$ the leukocyte counts on day 4 , and the number of lymphocytes on days 4 , and 29 were significantly lower than in the control group (Figure 5).

$\mathrm{BE}$ alone had no effect on leukocyte and lymphocyte counts in peripheral blood in rats treated at the dose of $0.75 \mathrm{mM} / \mathrm{kg}$ and $1.25 \mathrm{mM} / \mathrm{kg}$ for 28 days.

In the rats simultaneously exposed to ethanol and BE at the dose of $0.75 \mathrm{mM} / \mathrm{kg}$ and $1.25 \mathrm{mM} / \mathrm{kg}$ the number of both leukocytes and lymphocytes in peripheral blood were similar as in the control group.

\section{DISCUSSION}

The aim of the present work was to assess the effect of ethanol drinking on hemolytic action of EGAEs in rats. The experimental protocol applied in this experiment aimed at the constitution of a model of conditions that may take place in human life.

The treatment with ethanol may be tantamount to its misuse in man. The daily consumption of ethanol in the rats drinking $10 \%(\mathrm{w} / \mathrm{v})$ water solution of ethanol was equivalent to about $0.7 \mathrm{l} /$ day of $40 \%$ vodka in men [22]. Since the rate of ethanol oxidation in rats $(0.3 \mathrm{~g} / \mathrm{kg} / \mathrm{h})$ is three times faster than in humans, these animals needed a higher dose of ethanol to produce comparable toxic effects.

The rats simultaneously treated with EGAEs and ethanol consumed similar quantity of ethanol as in the control group. Food intake in these animals was diminished in each experimental group in relation to both control and ethanol groups. The reduction in food intake was most pronounced at the highest dose of $\mathrm{ME}, \mathrm{EE}$, and $\mathrm{BE}$, i.e., 5.0, 5.0, and $1.25 \mathrm{mM} / \mathrm{kg}$, respectively. The growth retardation in rats simultaneously exposed to EGAEs and ethanol was observed. It was most likely to be caused by the reduced food consumption observed in these animals. Although ethanol has been reported to cause anorexia and weight loss [23,24], it seems that EGAEs alone may be one of the main reasons for retardation of body weight gain. The body weight alterations observed previously in rats exposed to EGAEs alone [6] seem to confirm of this suggestion.

In the present study, it was found that subcutaneous repeated administration of each of three EGAEs led to distinct hematological alterations. These alterations were evidenced by reduction in $\mathrm{RBC}, \mathrm{PCV}$, and $\mathrm{HGB}$, and also by an increase in MCV value and Ret in peripheral 


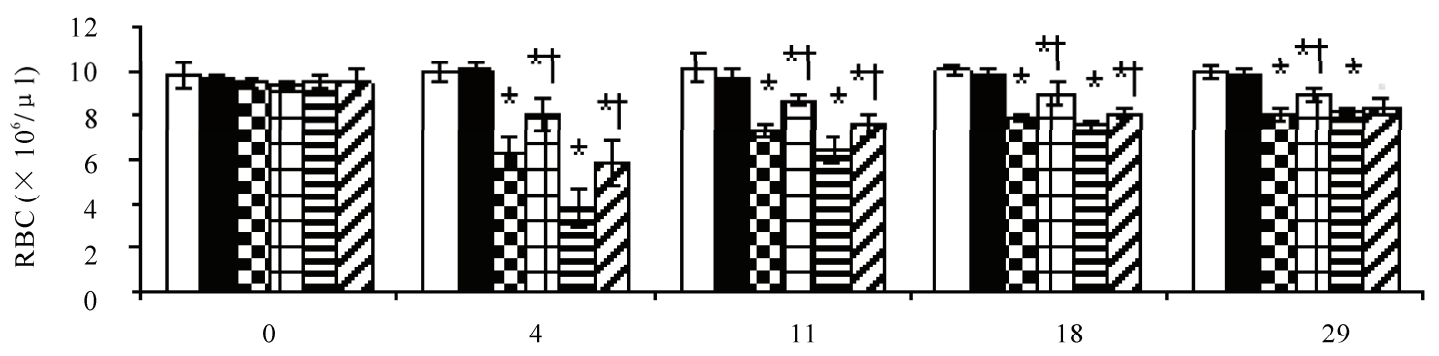

(a)
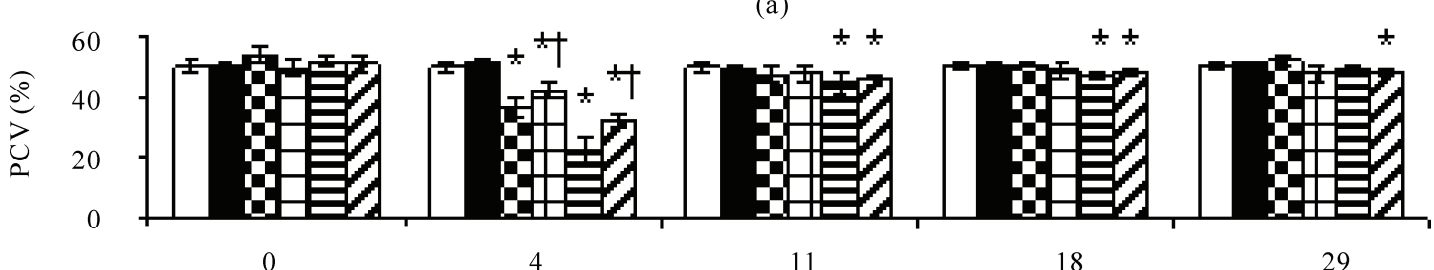

11

18

29

(b)

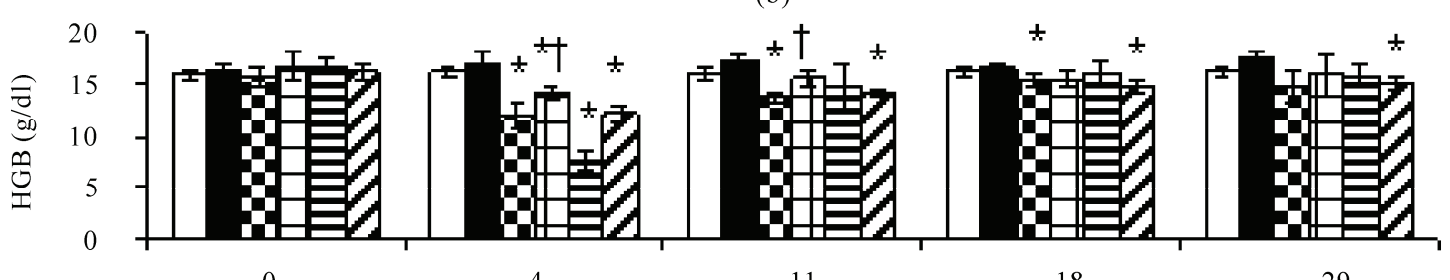

0

4

11

18

29

(c)
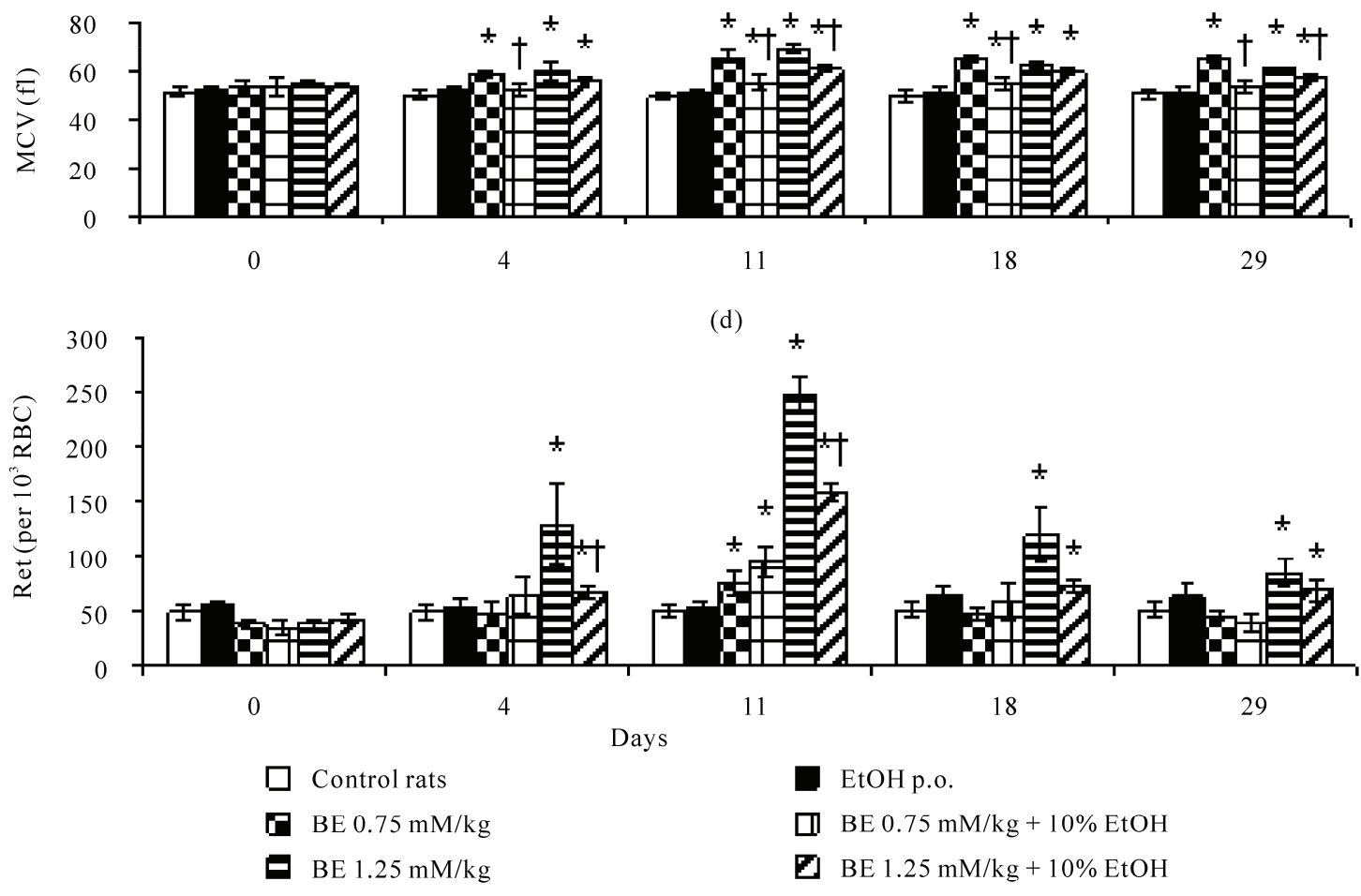

(d) $\quad+$

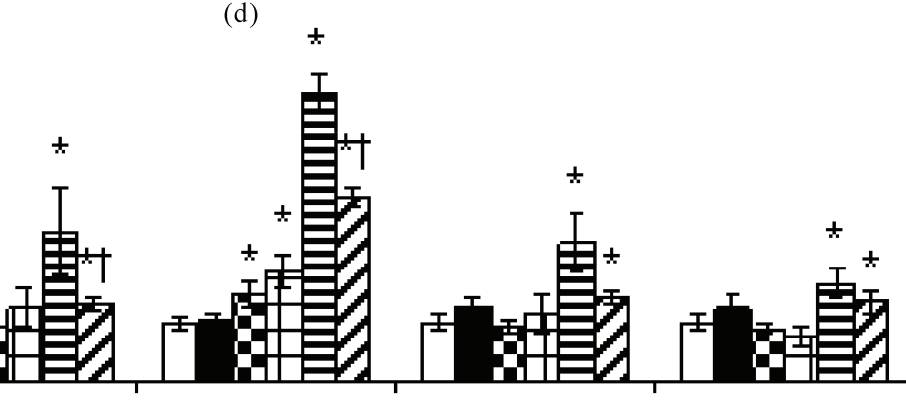

11

18

29

Days

EtOH p.o.
ㅁ] BE $0.75 \mathrm{mM} / \mathrm{kg}+10 \%$ EtOH
घ BE $1.25 \mathrm{mM} / \mathrm{kg}+10 \%$ EtOH

(e)

Figure 3. Effects of ethanol (EtOH) consumption on RBC (a), PCV (b), HGB (c), MCV (d) and Ret (e) values of the peripheral blood at the designated time points of male rats treated with buthoxyethanol (BE) at doses $0.75 \mathrm{mM} / \mathrm{kg}$ b.w. or $1.25 \mathrm{mM} / \mathrm{kg}$ b.w. The values are means $\pm \mathrm{SD}$ of five rats, $*-\mathrm{P} \leq 0,05$ significantly different from control rats; $\uparrow-$ $\mathrm{P} \leq 0.05$ significantly different from rats treated with $\mathrm{BE}$ alone. 


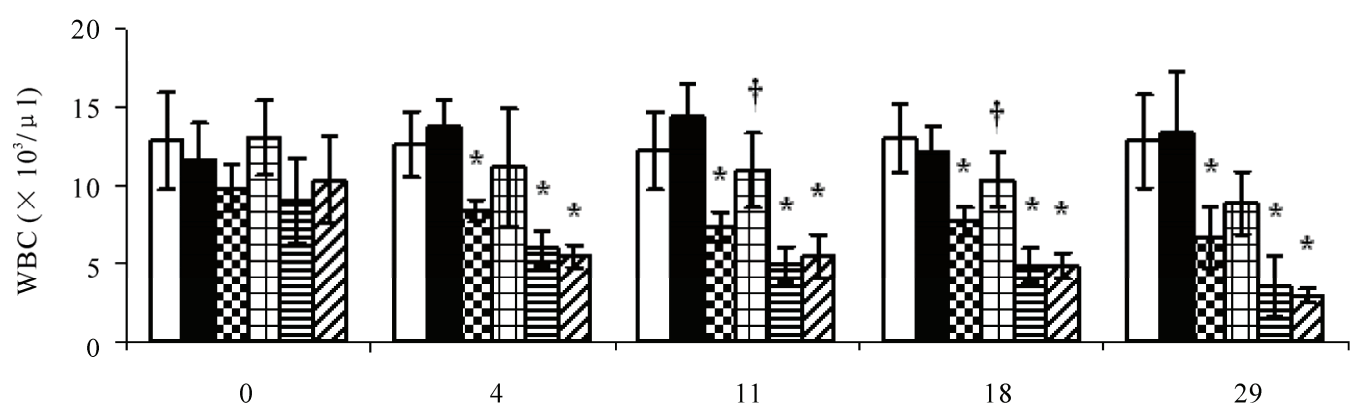

(a)

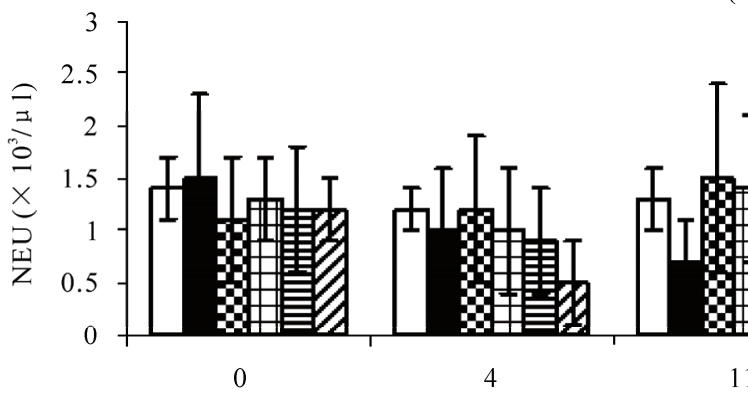

(b)

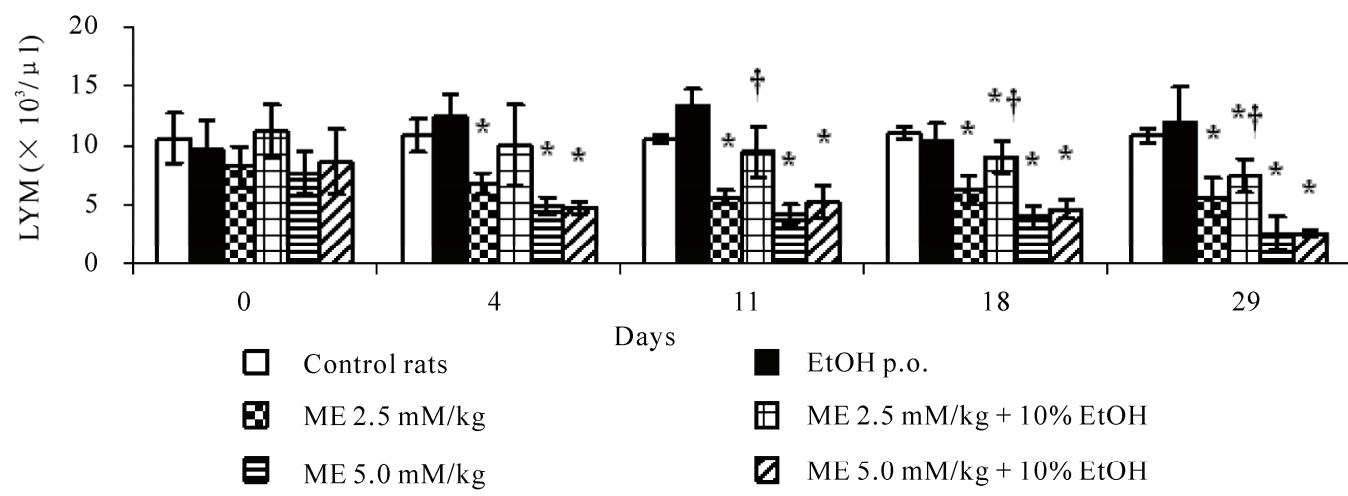

(c)

Figure 4. Effects of ethanol (EtOH) consumption on WBC (a), NEU (b) and LYM (c) values of the peripheral blood at the designated time points of male rats treated with methoxyethanol (ME) at doses $2.5 \mathrm{mM} / \mathrm{kg} \mathrm{b}$.w. or $5.0 \mathrm{mM} / \mathrm{kg}$ b.w. The values are means $\pm \mathrm{SD}$ of five rats, *-P $\leq 0,05$ significantly different from control rats; $\uparrow-\mathrm{P} \leq 0,05$ significantly different from rats treated with ME alone.

blood. While in rats treated with ME these changes were strongly pronounced and progressively increased with exposure time beginning from the day 11, those in animals treated with EE were less pronounced and rather persisted at low constant level for the whole exposure period. On the contrary, the rats treated with BE demonstrated the distinct intravascular hemolysis resulted in hemolytic anemia at the beginning of exposure (on day 4). Independently of exposure duration, these alterations were regressed, although the decrease in $\mathrm{RBC}$ and the increase in MCV were more persistent, probably due to the selective hemolysis of the aged erythrocytes [25], leaving a population of young red cells. Hemoglobinuria observed only in the first day of exposure to $\mathrm{BE}$ at dose of $1.25 \mathrm{mM} / \mathrm{kg}$ seems to confirm of this suggestion. The various hematological changes observed during exposure to EGAEs are typical of hemolytic anemia with an associated reticulocytosis and hyperplasia of both bone marrow (erythroid elements) and spleen (extramedullary hemopoiesis) [26].

The results presented in this paper confirm previous observations that continued exposure to $\mathrm{BE}$, contrary to $\mathrm{ME}$ and $\mathrm{EE}$, resulted in significantly less pronounced hematological changes [6]. While the majority of hematological effects were dramatic at the beginning of the exposure, later these alterations clearly regressed despite continued weekly exposure to these compounds. It was suggested that the gradual recovery from the haemolytic 


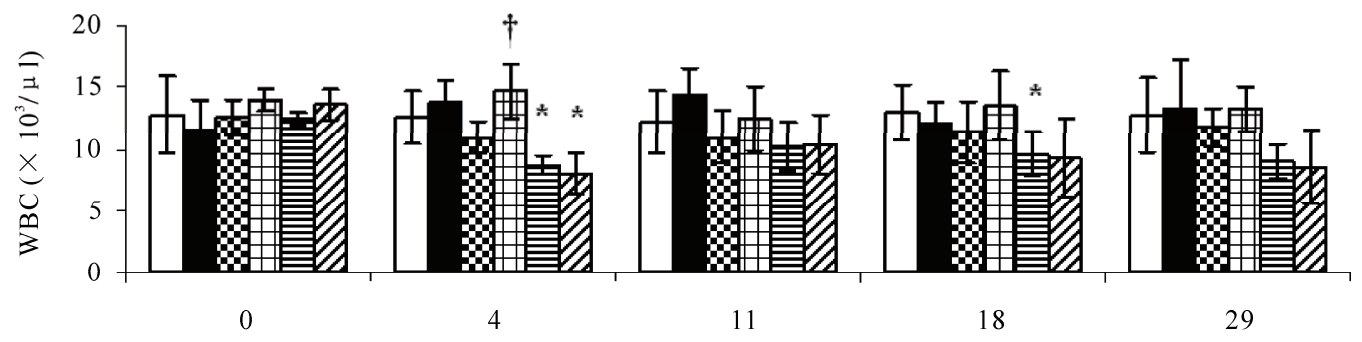

(a)

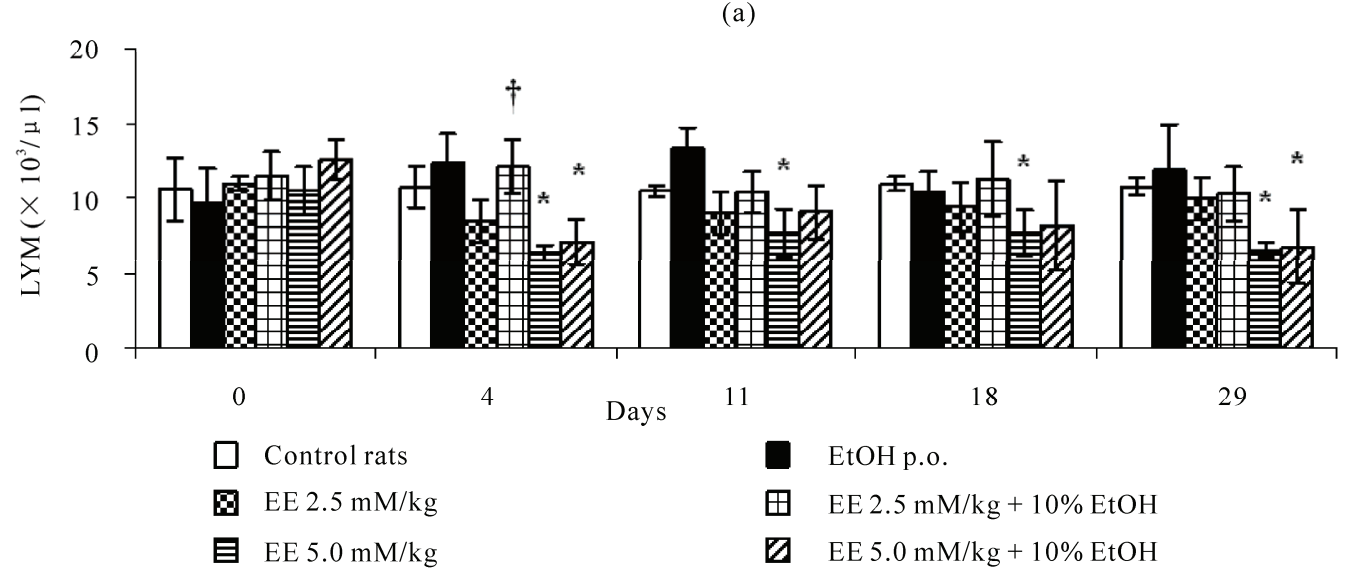

(b)

Figure 5. Effects of ethanol (EtOH) consumption on WBC (a) and LYM (b) values of the peripheral blood at the designated time points of male rats treated with ethoxyethanol (EE) at doses $2.5 \mathrm{mM} / \mathrm{kg} \mathrm{b.w}$. or $5.0 \mathrm{mM} / \mathrm{kg} \mathrm{b}$.w. The values are means $\pm \mathrm{SD}$ of five rats, $*-\mathrm{P} \leq 0.05$ significantly different from control rats; $\uparrow-\mathrm{P} \leq 0.05$ significantly different from rats treated with $\mathrm{EE}$ alone.

anemia may be associated with tolerance development to the hemolytic effect of BE. This tolerance was characterrized by a progressive removal of hematological changes, manifested in an increase of RBC, PCV, HGB, and a decrease in Ret value in peripheral blood. The tolerance to BE-induced hemolytic anemia was also observed in other studies $[27,28]$. Moreover, our studies demonstrated that the effects of repeated exposure for 28 days to $\mathrm{BE}$ were less pronounced than the effects of single doses of this ether at the same or comparable doses [29,30].

The changes in the leukocyte system of rats were produced by two of three EGAEs, but there were marked quantitative differences in the responses. While ME strongly suppressed this system causing leukopenia, lymphocytopenia, and neutrocytopenia, EE at the higher dose $(5.0 \mathrm{mmol} / \mathrm{kg})$ only, exerted the middle inhibitory effect resulted in the occasional reduction of leukocytes with a simultaneous decrease in the number of lymphocytes at each time point of the exposure. In contrast, BE caused no changes in the leukocyte system. These results are inconsistent with the data of Grant et al. [26] which observed inhibitory effects of ME and BE on leukocyte system in rats. This inconsistency concerning BE only, may be due to considerably higher doses of this compound administered to rats, reported in the paper cited.
The literature data [26,31] indicate that ME is immunotoxic. Dermal exposure of rats to this compound at dose levels in a range of $2-16 \mathrm{mM} / \mathrm{kg} /$ day for four consecutive days produce droplets in thymus and spleen weight, enhanced the lymphoproliferative responses to mitogens, and a reduction in the antibody plaque-forming cell response to either trinitrophenyl-lipopolysaccharide or sheep RBC. Miller et al. [32] observed lymphoid tissue atrophy after inhalation of ME in male New Zealand white rabbits. Also Smialowicz et al. [33,34] reported a marked immunosuppressive effects of ME and both MAA and methoxyacetaldehyde, the metabolites of ME, on thymus weight and lymphoproliferative functions in rats.

There is still too little knowledge on the effects of ethanol on EGAEs-toxicity, especially on hematological changes. Morel et al. [21] did not observed the effects of three aliphatic alcohols, i.e., ethanol, n-propanol, and n-butanol, at dose of 10 or $30 \mathrm{mmol} / \mathrm{kg}$, on the urinary creatine/creatinine ratio, the testicular toxicity or the 24 $\mathrm{h}$ urinary excretion of MAA in rats after simultaneous treatment with a single dose of ME $(10 \mathrm{mM} / \mathrm{kg})$ by gavage. On the other hand, the simultaneous administration of $30 \mathrm{mM} / \mathrm{kg}$ of above mentioned alcohols almost totally inhibited the hemolytic effect of BE (5 or $1 \mathrm{mM} / \mathrm{kg}$ ), and 
reduced the urinary excretion of BAA, metabolite of this compound, by 31-43\%. It was suggested that competitive inhibition of ADH by alcohols results in the change in $\mathrm{BE}$ metabolism.

The results of the present study indicate that ethanol alone consumption did not have any effect on examined hematological parameters. However, ethanol intake along with EGAEs, only partially protected the rats against hemolytic effects and the alterations in leukocyte system induced by these ethers. The preventive effect was seen at both lower and higher doses of $\mathrm{ME}$ (2.5 and 5.0 $\mathrm{mM} / \mathrm{kg})$ and $\mathrm{BE}(0.75$ and $1.25 \mathrm{mM} / \mathrm{kg})$, as well as at the higher dose of EE $(5.0 \mathrm{mM} / \mathrm{kg})$, while in rats simultaneously exposed to ethanol and both $\mathrm{ME}$ and $\mathrm{EE}$ at the lower dose $(2.5 \mathrm{mM} / \mathrm{kg})$, mainly protection from the alteration in leukocyte system was observed. In contrast, the rats which consumed ethanol and simultaneously were treated with the higher dose of ME or EE (5.0 $\mathrm{mM} / \mathrm{kg}$ ), demonstrated the amelioration of these hematological parameters (RBC, PCV, and HGB) in relation to the animals exposed to these compounds alone. On the other hand, ethanol intake along with BE treatment (both 0.75 and $1.25 \mathrm{mM} / \mathrm{kg}$ ) markedly ameliorated hematological parameters, especially RBC, PCV, HGB, $\mathrm{MCV}$, and Ret in comparison with the group exposed to this ether alone.

The results presented in this paper clearly demonstrate that ethanol modifies the hematological effects of continued exposure to EGAEs. The explanation the biological basis of the interactions between ethanol and EGAEs may be related to the metabolism of these compounds. The glycol ethers, especially EE, BE, and 2-phenoxyethanol, are metabolized in vitro by rat hepatic and cutaneous cytosolic preparations in the reaction involving $\mathrm{ADH}$ and ALDH in both tissues [35]. Hepatic cytosol metabolizes ethanol in preference to intermediate chainlength EGAEs, whereas the skin cytosol preferentially metabolizes the glycol ethers. It was found that EGAEs oxidation is performed predominantly by $\mathrm{ADH} 3$, and ALDH1 isoenzymes. Repeated exposure to EGAEs results in induction of these enzymes. The rates of ADH oxidation by rat liver cytosol were the greatest for ethanol followed by EE and BE. In contrast, the order of metabolism by rat skin cytosolic fraction was changed to $\mathrm{BE}>\mathrm{EE}>$ ethanol [35]. Although skin contains enzymes that have the capacity to biotransformation EGAEs localized in the basal layer of the epidermis [36], the physicochemical properties of these compounds result in rapid penetration and distinct reduction in dermal metabolism during their percutaneous absorption [37]. Thus, EGAEs are mainly metabolized in the liver similarly as ethanol.

In conclusion, the decrease of the hemolytic effects due to EGAEs is ethanol dependent. Ethanol is a substrate of $\mathrm{ADH}$, and the affinity of this enzyme is higher than those of glycol ethers. It is possible that ethanol results in the change in EGAEs metabolism. The difference between EGAEs metabolism may be one of the reasons for the differences observed between $\mathrm{ME}, \mathrm{EE}$, and $\mathrm{BE}$ in the interaction of ethanol.

\section{ACKNOWLEDGEMENTS}

This paper has been prepared on the basis of the results of a research task 2.R.05 carried out within the scope of the first stage of the National Programme "Improvement of safety and working conditions" supported in 2008-2010 - within the scope of research and development - by the Ministry of Science and Higher Education.

\section{REFERENCES}

[1] Raymond, L.W., Williford, L.S. and Burke, W.A. (1998) Eruptive cherry angiomas and irritant symptoms after one acute exposure to the glycol ether solvent 2-butoxyethanol. Journal of Occupational and Environmental Medicine, 40(12), 1059-1064.

[2] Hardin, B.D., Goad, P.T. and Burg, J.A.R. (1984) Developmental toxicity of four glycol ethers applied cutaneously to rats. Environmental Health Perspectives, 57, 6974.

[3] Foster, P., Lloyd, S.C. and Blackburn, D.M. (1987) Comparison of the in vivo and in vitro testicular effects produced by methoxy-, ethoxy- and $\mathrm{N}$-butoxyacetic acids in the rat. Toxicology, 43, 17-30.

[4] Wier, P.J., Lewis, S.C. and Traul, K.A. (1987) A comparison of developmental toxicity evident at term to postnatal growth and survival using ethylene glycol monoethyl ether, ethylene glycol monobutyl ether and ethanol. Teratogenesis, Carcinogenesis and Mutagenesis, 7(1), 55-64.

[5] Ghanayem, B.I., Long, P.H., Ward, S.M., Chanas, B., Nyska, M. and Nyska, A. (2001) "Hemolytic anemia thrombosis, and infarction in male and female F344 rats following gavage exposure to 2-butoxyethanol. Experimental and Toxicologic Pathology, 53(2-3), 97-105.

[6] Starek, A., Szymczak, W. and Zapór, L. (2008) Hematological effects of four ethylene glycol monoalkyl ethers in short-term repeated exposure in rats. Archives of Toxicology, 82(2), 125-136.

[7] Cohen, R. (1984) Reversible subacute ethylene glycol monomethyl ether toxicity associated with microfilm production, a case report. American Journal of Industrial Medicine, 6, 441-446.

[8] Larese, F., Fiorito, A. and Zotti, R.D. (1992) The possible haematological effects of glycol monomethyl ether in a frame factory. British Journal of Industrial Medicine, 49, 131-133.

[9] Shih, T.-S., Hsieh, A.-T., Liao, G.-D., Chen, Y.-H. and Liou, S.-H. (2000) Haematological and spermatotoxic effects of ethylene glycol monomethyl ether in copper clad laminate factories. Occupational and Environmental Medicine, 57, 348-352. 
[10] Shih, T.-S., Hsieh, A.-T., Chen, Y.-H., Liao, G.-D., Chen, C.-Y., Chou, J.-S. and Liou, S.-H. (2003) Follow up study of haematological effects in workers exposed to 2-methoxyethanol. Occupational and Environmental Medicine, 60, 130-135.

[11] Kim, Y., Lee, N., Sakai, T., Kim, K.S., Yang, J.S., Park, S., Lee, C.R., Cheong, H.K. and Moon, Y. (1999) Evaluation of exposure to ethylene glycol monoethyl ether acetates and their possible haematological effects on shipyard painters. Occupational and Environmental Medicine, 56(6), 378-382.

[12] Wang, R.S., Suda, M., Gao, X., Wang, B., Nakajima, T. and Honma, T. (2004) Health effects of exposure to ethylene glycol monoethyl ether in female workers. Industrial Health, 42(4), 447-451.

[13] Haufroid, V., Thirion, F., Mertens, P., Buchet, J.-P. and Lison, D. (1997) Biological monitoring of workers exposed to low levels of 2-butoxyethanol. International Archives of Occupational and Environmental Health, 70(4), 232-236

[14] Ghanayem, B.I., Burka, L.T. and Mattews, H.B. (1989) Structure-activity relationship for the in vitro hematotoxicity of N-alkoxyacetic acids, the toxic metabolites of glycol ethers. Chemico-Biological Interactions, 70(3-4), 339-352.

[15] Dartsch, P.C., Hildenbrand, S., Gfrorer, W., Kimmel, R. and Schmahl, F.W. (1999) Cytotoxic effects of 2-butoxyethanol in vitro are related to butoxyacetaldehyde, an intermediate oxidation product. Environmental Toxicology and Pharmacology, 7(2), 135-142.

[16] Moss, E.J., Thomas, L.V., Cook, W.M., Walters, D.G., Foster, P.M.D., Creasy, D.M. and Gray, T.J.B. (1985) The role of metabolism in 2-methoxyethanol induced testicular toxicity. Toxicology and Applied Pharmacology, 79(3), 480-489.

[17] Ghanayem, B.I., Burka, L.T. and Matthews, H.B. (1987) Metabolic basis of ethylene glycol monobutyl ether (2-butoxyethanol) toxicity, role of alcohol and aldehyde dehydrogenases. The Journal of Pharmacology and Experimental Therapeutics, 242(1), 222-231.

[18] Nagano, K., Nakayama, E., Oobayashi, H., Nishizawa, T., Okuda, H. and Yamazaki, K. (1984) Experimental studies on toxicity of ethylene glycol alkyl ethers in Japan. Environmental Health Perspectives, 57, 75-84.

[19] Starek, A., Szabla, J. and Starek-Świechowicz, B. (2007) Pyrazole and methylpyrazole for the treatment of 2-butoxyethanol poisoning. Acta Poloniae Pharmaceutica, 64(1), 93-100.

[20] Römer, K.G., Balge, F. and Freundt, K.J. (1985) Ethanol induced accumulation of ethylene glycol monoalkyl ethers in rats. Drug and Chemical Toxicology, 8(4), 255264.

[21] Morel, G., Lambert, A.M., Rieger, B. and Subra, I. (1996) Interactive effect of combined exposure to glycol ethers and alcohols on toxicodynamic and toxicokinetic parameters. Archives of Toxicology, 70, 519-525.

[22] Wiśniewska-Knypl, J.M. and Wrońska-Nofer, T. (1994) Biological markers of oxidative stress induced by ethanol and iron overload in rats. International Journal of Occupational Medicine \& Environmental Health, 7, 355-363.

[23] Strbak, V., Benicky, J., Macho, L., Jezova, D. and Nikodemova, M. (1998) Four-week ethanol intake decreases food intake and body weight but does not affect plasma leptin, corticosterone, and insulin levels in pubertal rats. Metabolism, 47(6), 1269-1273.

[24] Gupta, V. and Gill, K.D. (2000) Influence of ethanol on lead distribution and biochemical changes in rats exposed to lead. Alcohol, 20, 9-17.

[25] Carpenter, C.P., Pozzani, U.C., Weil, C.S., Nair, J.H. and Keck, G.A. (1956) The toxicity of butyl cellosolve solvent. A.M.A. Archives of Industrial Health, 14(2), 114131.

[26] Grant, D., Sulsh, S., Jones, H.B., Gangolli, S.D. and Butler, W.H. (1985) Acute toxicity and recovery in the hemopoietic system of rats after treatment with ethylene glycol monomethyl and monobutyl ethers. Toxicology and Applied Pharmacology, 77(2), 187-200.

[27] Krasavage, W.J. (1986) Subchronic oral toxicity of ethylene glycol monobutyl ether in male rats. Fundamental and Applied Toxicology, 6(2), 349-355.

[28] Ghanayem, B.I., Ward, S.M., Blair, P.C. and Matthews, H.B. (1990) Comparison of the hematologic effects of 2-butoxyethanol using two types of hematology analyzers. Toxicology and Applied Pharmacology, 106(2), 341345.

[29] Starek, A., Jarosz, J. and Szymczak, W. (2004) Comparison of the hemolytic activity of isopropoxyethanol and phenoxyethanol. International Journal of Occupational Medicine \& Environmental Health, 17, 339-346.

[30] Starek, A., Szabla, J., Szymczak, W. and Zapór, J. (2006) Comparison of acute haematotoxicity of 2-methoxyethanol, 2-ethoxyethanol and 2-butoxyethanol in male rats. Acta Toxicoogica, 14, 63-71.

[31] Williams, W.C., Riddle, M.M., Copeland, C.B., Andrews, D.L., Smialowicz, R.J. (1995) Immunological effects of 2-methoxyethanol administered dermally or orally to Fischer 344 rats. Toxicology, 98(1-3), 215-223.

[32] Miller, R.R., Hermann, E.A., Young, J.T., Landry, T.D. and Calhoun, L.L. (1984) Ethylene glycol monomethyl ether and propylene glycol monomethyl ether, metabolism, disposition, and subchronic inhalation toxicity studies. Environmental Health Perspectives, 57, 233-239.

[33] Smialowicz, R.J., Williams, W.C., Riddle, M.M., Andrews, D.L., Luebeke, R.W. and Copeland, C.B. (1992) Comparative immunosuppression of various glycol ethers orally administered to Fischer 344 rats. Fundamental and Applied Toxicology, 18(4), 621-627.

[34] Smialowicz, R.J., Riddle, M.M. and Williams, W.C. (1993) Methoxyacetaldehyde, an intermediate metabolite of 2-methoxyethanol, is immunosuppressive in the rat. Fundamental and Applied Toxicology, 21(1), 1-7.

[35] Lockley, D.J., Howes, D. and Williams, F.M. (2005) Cutaneous metabolism of glycol ethers. Archives of Toxicology, 79(3), 160-168.

[36] Coomes, M.W., Norling, A., Pohl, R.J., Muller, D. and Fouts, I.R. (1983) Foreign compound metabolism by isolated skin cells from the hairless mouse. The Journal of Pharmacology and Experimental Therapeutics, 225(3), 770-777.

[37] Lockley, D.J., Howes, D. and Williams, F.M. (2002) Percutaneous penetration and metabolism of 2-ethoxyethanol. Toxicology and Applied Pharmacology, 180(2), 74-82. 